\title{
IMPLEMENTASI KURIKULUM ISMUBA DI SD MUHAMMADIYAH KARANGKAJEN YOGYAKARTA
}

\author{
Wasito \\ Program Studi Magister Pendidikan Agama Islam, Universitas Ahmad Dahlan Yogyakarta \\ Email : toshe83@,Yahoo.co.id. HP ; 085327711113
}

\begin{abstract}
The purpose of this study was to describe the implementation of the ISMUBA curriculum at Muhammadiyah Elementary School Karangkajen Yogyakarta. This study uses qualitative research. The location of this research at Muhammadiyah Elementary School of Karangkajen Yogyakarta. The data were collected through observation, interviews, and documentation. Data analysis conducted by researchers is to use inductive methods, namely the process of analyzing based on existing data or obtained later developed with certain patterns with the stages of reducing data, presenting data, and drawing conclusions. The results of the study shows that the implementation of the ISMUBA Curriculum at Muhammadiyah Elementary School in Karangkajen Yogyakarta as a whole meet the curriculum implementation standards. The disadvantage is consistency and continuity in implementation, then human Resources is not evenly distributed in quality. Another thing is that the habitual character becomes very strong like getting used to prayer in congregation and alms.
\end{abstract}

Keywords : Al-Islam curriculum, Kemuhammadiyahan, and

Arabic.

\begin{abstract}
ABSTRAK
Tujuan Penelitian ini adalah untuk mendeskripsikan implementasi kurikulum ISMUBA di SD Muhammadiyah Karangkajen Yogyakarta. Penelitian ini merupakan jenis penelitian kualitatif. Lokasi penelitian di SD Muhammadiyah Karangkajen Yogyakarta. Teknik pengumpulan data dengan wawancara, observasi dan dokumentasi. Analisis data yang dilakukan oleh peneliti adalah dengan menggunakan metode induktif yakni proses menganalisis berdasarkan pada data yang ada atau yang diperoleh selanjutnya dikembangkan dengan pola tertentu dengan tahapannya mereduksi data, penyajian data, dan penarikan kesimpulan. Hasil penelitian menunjukan implementasi Kurikulum ISMUBA di SD Muhammadiyah Karangkajen Yogyakarta secara keseluruhan memenuhi standar implementasi kurikulum. Kekurangannya adalah konsistensi dan berkesinambungan dalam pelaksanaan, selanjutnya SDM yang tidak merata secara kualitas. Hal lainnya adalah bahwa
\end{abstract}


pembiasaan karakter menjadi sangat kuat seperti membiasakan shalat berjamaah dan sedekah.

\section{Kata Kunci : Kurikulum Al-Islam, Kemuhammadiyahan, Bahasa Arab}

\section{PENDAHULUAN}

Desentralisasi pengelolaan pendidikan yang diharapkan dapat memenuhi kebutuhan dan kondisi daerah perlu segera dilaksanakan. Bukti nyata dari desentralisasi pengelolaan pendidikan ini adalah diberikannya kewenangan kepada sekolah untuk mengambil keputusan berkenaan dengan pengelolaan pendidikan, seperti dalam pengelolaan kurikulum, baik dalam penyusunannya maupun pelaksanaannya di sekolah. Kurikulum merupakan seperangkat rencana dan pengaturan mengenai tujuan, isi, dan bahan pelajaran serta cara yang digunakan sebagai pedoman penyelenggaraan kegiatan pembelajaran untuk mencapai tujuan pendidikan tertentu. Tujuan tertentu meliputi tujuan pendidikan nasional serta kesesuaian dengan kekhasan kondisi dan potensi arah, satuan pendidikan, dan peserta didik. Oleh sebab itu kurikulum disusun oleh satuan pendidikan untuk memungkinkan penyesuaian program pendidikan dengan kebutuhan dan potensi yang ada di daerah.

Kewenangan sekolah dalam menyusun kurikulum memungkinkan sekolah menyesuaikan dengan tuntutan kebutuhan siswa, keadaan sekolah, dan kondisi daerah. Dengan demikian daerah dan atau sekolah memiliki cukup kewenangan untuk merancang dan menentukan hal-hal yang diajarkan, pengelolaan pengalaman belajar, cara mengajar, dan menilai keberhasilan belajar mengajar. Diberikannya kewenagan itulah maka sekolah-sekolah Muhammadiyah dalam pengembangan dan implementasinya menggunakan dua kurikulum yakni kurikulum Nasional dan kurikulum Berdasarkan acuan Muhammadiyah disebut ISMUBA (Al-Islam, Kemuhammadiyahan dan Bahasa Arab ).

Hadirnya kurikulum ISMUBA sudah ada sejak sekolah-sekolah Muhammadiyah berdiri hal ini merupakan bagian dari upaya pembentukan peserta didik yang berkarakter,menjadi kaderkader bangsa yang Ulama-Intelek, Intelek-Ulama; Ilmu-Amaliah, Amal-Ilmiah. Dan ini sesuai Undang-undang SISDIKNAS Nomor 20 Tahun 2003) tentang Sistem Pendidikan Nasional bahwa pendidikan Nasional memiliki fungsi mengembangkan kemampuan peserta didik dan membentuk karakter yang bermartabat untuk mencerdaskan kehidupan bangsa,bertujuan untuk 
berkembangnya potensi peserta didik sehingga menjadi manusia yang beriman dan betaqwa kepada Tuhan Yang Maha Esa, memiliki Akhlakul Karimah, sehat, berilmu, kreatif, mandiri dan menjadi warga negara yang demokratis serta bertanggung jawab. Kemudian Pemerintah menguatkannya dengan melakukan tindak lanjut dengan munculnya kurikulum 13 atau lebih familiar dengan sebutan K13. Pada Kurikulum ini menitikberatkan pada karakter yang berorientasi pada tujuan dan fokus pada proses, sehingga bisa menghasilkan sebuah sistem pendidikan yang tepat guna dan efektif, dalam hal ini siswa tidak akan terbebani dan dapat merancang cita-cita mereka dengan akurat. Selanjutnya bahwa fokus dari penerapan kurikulum ini adalah pada empat kompetansi salah satunya adalah kompetensi Inti Spiritual. Kompetensi ini mengarahkan peserta didik untuk lebih dekat pada Allah Subhanahu Wata'ala. Bagaimana dalam bersikap ia mencerminkan seorang hamba Allah yang taat. Dengan pencapaian kompetensi ini tentunya kelak diharapkan para generasi penerus bangsa adalah generasi yang selalu ingat dan menerapkan setiap ajaran agamanya dengan baik.

Sekolah-sekolah dasar Muhammadiyah memiliki visi, misi yang berbeda-beda. Hal ini disesuaikan pada kultur sekolah masing-masing. Sehingga dalam implementasi kurikulum ISMUBA akan sangat dipengaruhi oleh kultur yang ada dalam sekolah itu. Kultur tersebut mencakup pola pikir,sikap,tingkah laku,dan praktik pendidikan warga sekolah (Ansyar, 2015). Sebagaimana contoh ada sekolah yang lebih condong dan mudah di dalam mengembangkan atau mendongkrak kompetensi kognitifnya daripada kompetensi lainnya, atau ada sekolah yang lebih mudah mengembangkan kompetensi skill peserta didiknya dari pada lainnya dan sebagainya. Kecendrungan tersebut bukan lantas menghilangkan kompetensi lainnya akan tetapi pada kompetensi tertentu sekolah tersebut lebih mudah dikembangkan. Salah satunya sekolah itu adalah SD Muhammadiyah Karangkajen Yogyakarta yang memiliki visi yakni terwujudnya kualitas pendidikan agama dan umum (akademik) untuk menghasilkan siswa yang cerdas, berprestasi dan berakhlak mulia. Berbagai upaya telah dilakukan untuk meraih atau menjalankan visi tersebut salah satunya merancang kurikulum ISMUBA yang disesuaikan dengan kultur sekolah..

Berdasarkan latar belakang di atas maka tujuan dari penelitian ini adalah untuk mendeskripsikan implementasi kurikulum ISMUBA di SD Muhammadiyah Karangkajen Yogyakarta.

\section{METODE}

Penelitian yang digunakan adalah jenis penelitian lapangan yang bersifat deskriptif. Penelitian merupakan penelitian yang ditujukan untuk menggambarkan fenomena-fenomena 
yang ada,yang berlangsung pada saat ini ataupun saat yang lampau (Nana Syaodih, 2010). Dalam penelitian ini adalah untuk menggambarkan pelaksanaan kurikulum ISMUBA di SD Muhammadiyah Karangkajen yang didalamnya terdapat tahap perencanaan, Proses pembelajaran, dan evaluasi.

\section{SUBYEK DAN OBJEK PENELITIAN}

1) Subyek

Dalam penelitian ini sumber penelitian atau sumber data adalah kepala sekolah dalam hal ini adalah kepala sekolah SD Muhammdiyah Karangkajen Yogyakarta, Wakil kepala Sekolah Bidang Kurikulum,Wakil Kepala Sekolah Bidang Kehidupan Islami dan guru-guru ISMUBA. Data tersebut berkaitan dengan keadaan sekolah secara umum, pelaksanaan kurikulum ISMUBA, dan perangkat-perangkat yang dibutuhkan lainnya.

2) Objek

Dalam penelitian ini objek penelitiannya adalah pelaksanaan kurikulum ISMUBA yang di dalamnya terdiri dari Perencanaan,Pelaksanaan,dan evaluasi.

\section{TEKNIK PENGUMPULAN DATA}

Untuk mendapatkan data yang akurat terkait objek penelitian maka teknik yang digunakan dalam pengumpulan data adalah wawancara, observasi, dan dokumentasi sebagai acuan dalam penelitian kualitatif. Data yang diperoleh berasal dari data yang bersifat primer yakni instrumen kurikulum ISMUBA SD Muhammadiyah Karangkajen Yogyakarta sedangkan data yang bersifat sekunder adalah implementasi atau dokumen dari pelaksanaan kurikulum ISMUBA tersebut baik yang berasal dari wawancara dengan guru-guru ISMUBA atau observasi dilapangan.

1) Wawancara

Metode wawancara dalam penelitian ini adalah wawancara tidak terstruktur (Sugiyono, 2012). wawancara ini untuk menggali informasi terkait dengan implementasi kurikulum ISMUBA bagaimana perencanaanya, pelaksanaan dan evaluasinya.

2) Observasi

Peneliti melakukan observasi partisipasif (Sugiyono, 2012). Dalam hal ini peneliti melakukan pengamatan kegiatan keagamaan siswa sebagai bagian dari implementasi kurikulum ISMUBA di SD Muhammadiyah Karangkajen Yogyakarta. 
3) Dokumentasi

Metode ini merupakan cara pengumpulan data yang hasilnya adalah berupa catatan-catatan penting berkaitan dengan masalah yang diteliti sehingga akan mendapatkan data yang lengkap (Suwandi, 2008). Data tersebut berupa struktur kurikulum, muatan kurikulum ISMUBA, program kegiatan terprogram dan tidak terprogram, instrumen lainnya terkait dengan kurikulum ISMUBA SD Muhammadiyah Karangkajen.

\section{UJI KEABSAHAN DATA}

Dalam uji keabsahan data ini peneliti melakukan triangulasi yakni dengan mengumpulkan data yang berbeda selanjutnya menyamakan hasil dari metode pengumpulan data yang berbeda tersebut, pengecekan teman sejawat yang dimaksud adalah pengambilan data dari sumber lain, dan perpanjangan pengamatan menambah atau memperpanjang pengamatan dengan lebih cermat (Suwandi, 2008).

\section{ANALISIS DATA}

Analisis data yang dilakukan oleh peneliti adalah dengan menggunakan metode induktif yakni proses menganalisis berdasarkan pada data yang ada atau yang diperoleh selanjutnya dikembangkan dengan pola tertentu dengan tahapannya mereduksi data, penyajian data, dan penarikan kesimpulan.

\section{HASIL DAN PEMBAHASAN}

\section{Implementasi Kurikulum}

Dalam Oxford Advance Learner's Dictionary dikemukakan bahwa implementasi adalah: "Outsome thing into effect" atau penerapan sesuatu yang memberikan efek. Implementasi kurikulum juga dapat diartikan sebagai aktualisasi kurikulum tertulis (written curriculum) dalam bentuk pembelajaran. Hal ini sejalan dengan apa yang diungkapkan Miller (1985), bahwa implementasi kurikulum merupakan suatu penerapan konsep ide program atau tatanan kurikulum ke dalam praktik pembelajaran atau berbagai kreativitas baru sehingga terjadinya perubahan pada sekelompok orang yang diharapkan untuk berubah.

Fullan dalam Hamalik (1999) mendefinisikan suatu gagasan, program atau kumpulan kegiatan yang baru bagi orang-orang yang berusaha atau diharapkan untuk berubah. Dengan demikian, implementasi kurikulum adalah penerapan atau pelaksanaan program kurikulum yang telah dikembangkan dalam tahap sebelumnya, kemudian diujicobakan dengan 
pelaksanaan dan pengelolaan yang disesuaikan terhadap situasi dan kondisi lapangan dan karakteristik peserta didik baik perkembangan intelektual, emosional, serta fisiknya.

\section{Prinsip-Prinsip Pelaksanaan Kurikulum}

Pelaksanaan kurikulum, didasari pada Permendiknas No.22 tahun 2006). Beberapa prinsip yang perlu diperhatikan disetiap satuan pendidikan sebagai berikut:

a. Pelaksanaan kurikulum didasarkan pada potensi, perkembangan dan kondisi peserta didik untuk menguasai kompetensi yang berguna bagi dirinya. Dalam hal ini peserta didik harus mendapatkan pelayanan pendidikan yang bermutu, serta memperoleh kesempatan untuk mengekspresikan dirinya secara bebas, dinamis dan menyenangkan.

b. Kurikulum dilaksanakan dengan menegakkan kelima pilar pelajar, yaitu: (a) belajar untuk beriman dan bertaqwa kepada Tuhan Yang Maha Esa, (b) belajar untuk memahami dan menghayati, (c) belajar untuk mampu melaksanakan dan berbuat secara efektif, (d) belajar untuk hidup bersama dan berguna pada orang lain, dan (e) belajar untuk membangun dan menemukan jati diri, melalui proses pembelajaran yang aktif, kreatif, efektif, dan menyenangkan.

c. Pelaksanaan kurikulum memungkinkan peserta didik mendapat pelayanan yang bersifat perbaikan, pengayaan, dan/atau percepatan sesuai dengan potensi, tahap perkembangan, dan kondisi peserta didik dengan tetap memperhatikan keterpaduan pengembangan pribadi peserta didik yang berdimensi ke-Tuhanan, keindividuan, kesosialan, dan moral.

d. Kurikulum dilaksanakan dalam suasana hubungan peserta didik dan pendidik yang saling menerima dan menghargai, akrab, terbuka, dan hangat, dengan prinsisp tut wuri handayani, ing madia mangun karsa, ing ngarsa sung tulada (di belakang memberikan daya dan kekutan, di tengah membangun semangat dan prakarsa, di depan memberi contoh dan teladan).

e. Kurikulum dilaksanakan dengan menggunakan pendekatan multistrategi dan multimedia, sumber belajar dan teknologi yang memadai, dan memanfaatkan alam sekitar sebagai sumber belajar, dengan prinsip alam takambang jadi guru (semua yang terjadi, tergelar dan berkembang di masyarakat dan lingkungan sekitar serta lingkungan alam semesta dijadikan sumber belajar, contoh dan teladan).

f. Kurikulum dilaksanakan dengan mendayagunakan kondisi alam, sosial dan budaya serta kekayaan daerah untuk keberhasilan pendidikan serta muatan seluruh bahan kajian secara optimal. 
g. Kurikulum yang mencakup seluruh komponen kompetensi mata pelajaran, muatan lokal dan pengembangan diri diselenggarakan dalam keseimbangan, keterkaitan, dan kesinambungan yang cocok dan memadai antar kelas dan jenis jenjang pendidikan.

Pelaksanaan kurikulum dibagi menjadi dua tingkatan, yaitu pelaksanaan kurikulum tingkat sekolah dan tingkat kelas. Dalam tingkat sekolah yang berperan adalah kepala sekolah dan pada tingkat kelas yang berperan adalah guru. Walaupun dibedakan antara tugas kepala sekolah dan tugas guru dalam pelaksanaan kurikulum serta diadakan perbedaan tingkat dalam pelaksanaan administrasi, yaitu tingkat kelas dan tingkat sekolah, tetapi antara kedua tingkat dalam pelaksanaan administrasi kurikulum tersebut senantiasa bergandengan dan bersama-sama bertanggung jawab melaksanakan proses administrasi kurikulum.

\section{Pelaksanaan Kurikulum Tingkat Sekolah}

Pada tingkat sekolah, kepala sekolah bertanggung jawab untuk melaksanakan kurikulum di lingkungan sekolah yang dipimpinnya. Tanggung jawab kepala sekolah adalah kepala sekolah sebagai pemimpin, sebagai administrator, penyusunan rencana tahunan, pembinaan organisasi sekolah, koordinator dalam pelaksanaan kurikulum, kegiatan memimpin rapat kurikuler, sistem komunikasi dan pembinaan kurikuler.

2. Pelaksanaan Kurikulum Tingkat Kelas

Pembagian tugas guru harus diatur secara administrasi untuk menjamin kelancaran pelaksanaan kurikulum lingkungan kelas. Pembagian tugas-tugas tersebut meliputi tiga jenis kegiatan administrasi, yaitu pembagian tugas mengajar, pembagian tugas-tugas pembinaan ekstrakurikuler, pembagian tugas bimbingan belajar.

\section{Tahap-Tahap Implementasi Kurikiulum}

Secara garis besar tahapan implementasi kurikulum meliputi tahap perencanaan, pelaksanaan dan evaluasi (Dinn Wahyudin, 2014).

1. Tahap Perencanaan Implementasi

Tahap ini bertujuan untuk menguraikan visi dan misi atau mengembangkan tujuan implementasi (operasional) yang ingin dicapai. Dalam setiap penetapan berbagai elemen yang akan digunakan dalam proses implementasi kurikulum terdapat tahapan proses pembuatan keputusan yang meliputi; 1) Identifikasi masalah yang dihadapi (tujuan yang ingin dicapai); 2) Pengembangan setiap alternatif metode, evaluasi, personalia, anggaran dan waktu, 3) Evaluasi setiap alternatif tersebut; 4) penentuan alternatif yang paling tepat. 
2. Tahap Pelaksanaan Implementasi

Tahap ini bertujuan untuk melaksanakan Blue Print yang telah disusun dalam perencanaan dengan menggunakan sejumlah teknik dan sumber daya yang ada dan telah ditentukan pada tahap perencanaan sebelumnya.

Pelaksanaan dilakukan oleh suatu tim terpadu, menurut departemen/divisi/seksi masingmasing atau gabungan, tergantung pada rencana sebelumnya, hasil dari pekerjaan ini adalah tercapainya tujuan-tujuan kegiatan yang telah ditetapkan.

3. Tahap Evaluasi Implementasi

Tahap ini bertujuan untuk melihat dua hal: 1) Melihat proses pelaksanaan yang sedang berjalan sebagai tugas kontrol, apakah pelaksanaan evaluasi telah sesuai dengan rencana dan sebagai fungsi perbaikan jika selama proses terdapat kekurangan. 2) Melihat hasil akhir yang dicapai. Hasil akhir ini merujuk pada kriteria waktu dan hasil yang dicapai dibandingkan terhadap fase perencanaan. Evaluasi dilaksanakan dengan menggunakan suatu metode, sarana dan prasarana, anggaran personal dan waktu yang ditentukan dalam tahap perencanaan.

\section{Implementasi Kurikulum Di SD Muhammadiyah Karangkajen Yogyakarta}

Dalam implementasi kurikulum ISMUBA di SD Muhammadiyah Karangkajen Yogyakarta terbagi dalam tiga tahap yakni perencanaan kurikulum, pelaksanaan kurikulum dan evaluasi pelaksanaan kurikulum.

\section{A. Perencanaan Kurikulum}

Dalam perencanaan ini meliputi penyusunan kurikulum ISMUBA yang dijabarkan sebagai berikut:

Struktur dan muatan Kurikulum pada jenjang pendidikan SD Muhammadiyah Karangkajen terdiri dari 2 kurikulum. Kelas I s.d V menggunakan kurikulum 2013 sedangkan Kelas VI menggunakan kurikulum KTSP 2006. 


\section{STRUKTUR KURIKULUM \\ SD MUHAMMADIYAH KARANGKAJEN YOGYAKARTA \\ TAHUN PELAJARAN 2018 / 2019}

\section{Rombongan belajar}

Kelas I

Kelas II

Kelas III

Kelas IV

Kelas V

$\underline{\text { Kelas VI }}$

Jumlah
: 2 Rombel

: 2 Rombel

: 3 Rombel

: 3 Rombel

: 3 Rombel

: 2 Rombel

: 15 Rombel

\begin{tabular}{|c|c|c|c|c|c|c|c|}
\hline \multirow{3}{*}{ NO } & \multirow{3}{*}{ MATA PELAJARAN } & \multicolumn{6}{|c|}{$\begin{array}{l}\text { ALOKASI WAKTU DAN } \\
\text { KELAS }\end{array}$} \\
\hline & & \multicolumn{6}{|c|}{ KUR. 2013} \\
\hline & & $\mathbf{I}$ & II & III & IV & $\mathbf{V}$ & VI \\
\hline $\mathbf{A}$ & KELOMPOK A & & & & & & \\
\hline 1 & Pendidikan Agama Islam & 4 & 4 & 4 & 4 & 4 & 4 \\
\hline 2 & Pendidikan Kewarganegaraan & 5 & 5 & 6 & 5 & 5 & 2 \\
\hline 3 & Bahasa Indonesia & 8 & 9 & 10 & 7 & 7 & 7 \\
\hline 4 & Matematika & 5 & 6 & 6 & 6 & 6 & 7 \\
\hline 5 & Ilmu Pengetahuan Alam & - & - & - & 3 & 3 & 6 \\
\hline 6 & Ilmu Pengetahuan Sosial & - & - & - & 3 & 3 & 3 \\
\hline B. & KELOMPOK B & & & & & & \\
\hline 7 & Seni Budaya dan Prakarya & 4 & 4 & 4 & 4 & 4 & 3 \\
\hline 8 & Pendidikan Jasmani, Olahraga, dan Kesehatan & 4 & 4 & 4 & 4 & 4 & 4 \\
\hline & Jumlah Alokasi Waktu Per Minggu & 30 & 32 & 34 & 36 & 36 & 36 \\
\hline B & MUATAN LOKAL & & & & & & \\
\hline 1 & $\begin{array}{l}\text { Bahasa Jawa } \\
\text { (Wajib ) }\end{array}$ & 2 & 2 & 2 & 2 & 2 & 2 \\
\hline
\end{tabular}




\begin{tabular}{|c|c|c|c|c|c|c|c|}
\hline 2 & $\begin{array}{l}\text { Seni Batik / Membatik } \\
\text { (Pilihan ) }\end{array}$ & - & - & - & 2 & 2 & 2 \\
\hline & JUMLAH JAM MENGAJAR TOTAL & 34 & 34 & 36 & 40 & 40 & 40 \\
\hline \multirow[t]{2}{*}{$\mathbf{C}$} & PENGEMBANGAN DIRI & & & & & & \\
\hline & $\begin{array}{ll}\text { (PROGRAM } & \text { PLUS } \\
\text { EKSTRAKURIKULER) } & \end{array}$ & & & & & & \\
\hline 1 & Iqro' & 8 & 8 & 8 & - & - & - \\
\hline 2 & Kepanduan HW/Pramuka & - & - & - & 2 & 2 & - \\
\hline 3 & Bahasa Inggris & 1 & 1 & 1 & 1 & 1 & 1 \\
\hline 4 & Kemuhammadiyahan & 1 & 1 & 1 & 1 & 1 & 1 \\
\hline 5 & Bahasa Arab & & & & 1 & 1 & 1 \\
\hline 6 & Drum Band & - & - & 2 & 2 & 2 & - \\
\hline 7 & Tapak Suci & - & - & 2 & - & - & - \\
\hline 8 & Murotal dan Tilawah & - & - & 2 & 2 & 2 & 2 \\
\hline 9 & Komputer / TI & - & 2 & 2 & 2 & 2 & 2 \\
\hline 10 & Seni Tari & - & 2 & 2 & 2 & - & - \\
\hline 11 & Futsal & - & - & - & 2 & 2 & 2 \\
\hline 12 & Renang & - & 2 & 2 & 2 & 2 & 2 \\
\hline 13 & Study Sain & - & - & - & 2 & 2 & 2 \\
\hline 14 & Study Inggris & - & 2 & 2 & 2 & 2 & 2 \\
\hline 15 & Murotal Ekselens & - & 2 & 2 & 2 & 2 & 2 \\
\hline 16 & Vokal & - & - & - & 2 & 2 & - \\
\hline 17 & Keybord & - & - & - & 2 & 2 & - \\
\hline
\end{tabular}

Keterangan :

*) Ekuivalen 2 jam pelajaran

1 Kelas I, II, III, Pembelajaran Tematik

2 Kelas IV,V,VI Pembelajaran Mapel

3 Ekstra Wajib dan Pilihan 
Keterangan :

1. Satu jam pelajaran 35 menit

2. Kelas 1 s.d. 5 mengacu Kurikulum 13

3. Jumlah minggu efektif satu tahun 36 sampai 40 minggu.

4. Sekolah memasukkan pendidikan yang berbasis keunggulan local dan global yang merupakan bagian dari mata pelajaran yang diunggulkan.

5. Pembelajaran berwawasan lingkungan dan pendidikan etika lalu lintas terintegrasi dalam setiap mata pembelajaran

\section{Muatan Kurikulum ISMUBA}

\section{Pendidikan Al-Islam}

Pendidikan Al-Islam memiliki tujuan sebagai berikut:

a) Menumbuh kembangkan akidah melalui pemberian, pemupukan, dan pengembangan pengetahuan, penghayatan, pengamalan, pembiasaan, serta pengalaman peserta didik tentang agama Islam sehingga menjadi manusia muslim yang terus berkembang keimanan dan ketaqwaannya kepada Allah SWT.

b) Mewujudkan manusia Indonesia yang taat beragama dan berakhlak mulia yaitu manusia yang berpengetahuan, rajin beribadah, cerdas, produktif, jujur, adil, etis, berdisiplin, bertoleransi (tasamuh), menjaga keharmonisan secara personal dan sosial serta mengembangkan budaya agama dalam komunitas sekolah.

\section{Kemuhammadiyahan dan Bahasa Arab}

Kemuhammadiyahan dan Bahasa Arab merupakan ciri khusus sekolah-sekolah Muhammadiyah begitu pula SD Muhammadiyah Karangkajen dengan tujuan:

a) Membekali peserta didik menjadi penerus dan kader muhammadiyah dengan menjunjung tinggi ciri khas dengan pendalaman agama Islam, kemuhammadiyahan dan bahasa arab.

b) Menyiapkan peserta didik yang berkarakter kuat dan berakhlak mulia melalui pelajaran Al Islam dengan pendalaman materi Al Qur'an Al hadits Aqidah, Ibadah, dan Akhlak.

c) Menyiapkan peserta didik agar dapat meneruskan amal usaha muhammadiyah dengan mengenal organisasi Muhammadiyah melalui pelajaran Kemuhammadiyahan. 
d) Membekali peserta didik dengan bahasa Arab agar dapat memudahkan dalam memahami kitab suci Al Quran

e) Menyiapkan peserta didik agar dapat meneruskan sekolah kejenjang yang lebih tinggi berbasis agama Islam utamanya sekolah-sekolah Muhammadiyah.

\section{Tuntas Iqra'}

Dalam pembelajaran tuntas Iqra', sekolah berkerjasama dengan lembaga Kibar untuk mendidik peserta didik khususnya kelas I dan kelas II agar peserta didik mampu membaca Al-quran dengan baik dan benar. Adapun tujuan dari tuntas Iqra' ini adalah:

1) Peserta didik terbiasa untuk mempelajari Al-quran

2) Membiasaan diri untuk bertadarus

3) Peserta didik mampu membaca Al-quran dengan baik dan benar

4) Ketika naik ke Kelas III seluruh siswa sudah bisa membaca Al-quran

\section{Kelas Tahfidz}

Dalam pelaksanaanya dimulai kelas 1 sampai kelas 6. Siswa kelas 1 dan kelas 2 dibimbing bersamaan dengan kegiatan tuntas Iqra', sedangkan kelas 3 sampai kelas 6 ada kelas khusus dalam membimbing para siswa untuk menghafal Al-quran dengan target hafal juz 30 dan juz 29.

\section{Kegiatan Pengembangan Diri}

Pengembangan diri merupakan sebuah kegiatan yang bertujuan untuk mengembangkan kemampuan peserta didik sesuai kemampuan, bakat, minat peserta didik sesuai dengan kondisi lingkungan satuan pendidikan. Kegiatan pengembangan diri dibimbing oleh konselor, guru, tenaga kependidikan maupun profesional yang ahli dibidangnya dalam bentuk ektrakurikuler. Penilaian kegiatan pengembangan diri dilakukan secara kualitatif yang difokuskan pada perubahan sikap dan tingkah laku setelah mengikuti program pengembangan diri.

Pengembangan diri di SD Muhammadiyah Karangkajen Yogyakarta meliputi kegiatan terprogram dan tidak terprogram. Kegiatan terprogram direncanakan secara khusus dan diikuti oleh peserta didik sesuai dengan kebutuhan dan kondisi pribadinya yang dituangkan dalam bentuk ekstrakurikuler wajib dan pilihan. Ekstrakurikuler wajib diikuti oleh semua peserta didik dalam jenjang tertentu, sedangkan ektrakurikuler pilihan dapat dipilih sesuai dengan bakat dan minatnya. 
Kegiatan tidak terprogram merupakan program pembinaan karakter yang bersifat pembiasaan agar peserta didik memiliki akhlaq mulia yang dilakukan secara rutin, spontan dan keteladanan. Kegiatan tersebut dilaksanakan secara langsung oleh pendidik dan tenaga kependidikan di sekolah/madrasah yang diikuti oleh semua peserta didik. Pengembangan diri diarahkan untuk pengembangan pendidikan karakter peserta didik yang ditujukan untuk kecakapan hidup dalam mengatasi persoalan dirinya, persoalan masyarakat di lingkungan sekitarnya, persoalan kebangsaan dan keumatan.

\section{a. Kegiatan Terprogram}

Kegiatan terprogram meliputi tiga komponen:

1) Pendalaman materi

Semua materi pelajaran, salah satunya adalah materi pelajaran ISMUBA. Pendalaman materi diberikan setelah jam belajar formal.

2) Ekstrakurikuler

Kegiatan ekstrakurikuler dilaksanakan di luar kelas diasuh oleh guru pembina. Kegiatan ekstrakurikuler meliputi beberapa jenis kegiatan yaitu:

\section{Pengembangan diri keislaman}

\begin{tabular}{|c|l|c|c|c|c|}
\hline No & \multicolumn{1}{|c|}{ Kegiatan } & Sasaran & Hari & Waktu & Ket. \\
\hline 1 & Tilawatil Qur'an & Kelas II - V & Sabtu & $14.15-15.45$ & Pilihan \\
\hline 2 & Tafidzul Qur'an & Kelas III - V & Rabu & $14.15-15.45$ & Pilihan \\
\hline 3 & Tartilul Qur'an & Kelas II - V & $\begin{array}{c}\text { Selasa \& } \\
\text { Kamis }\end{array}$ & $14.15-15.45$ & Pilihan \\
\hline 4 & TPA Terpadu & Kelas II - IV & $\begin{array}{c}\text { Selasa \& } \\
\text { Kamis }\end{array}$ & $14.15-15.45$ & Pilihan \\
\hline 5. & $\begin{array}{l}\text { Pembinaan lomba- } \\
\text { lomba Keagamaan }\end{array}$ & III-VI & Sabtu & $07.30-10.00$ & Terpilih \\
\hline
\end{tabular}

\section{b. Kegiatan tidak terprogram}

Kegiatan tidak terprogram merupakan pembiasaan pendidikan karakter peserta didik yang dilaksanakan oleh guru maupun tenaga kependidikan, terjadwal dan tidak terjadwal. Program pembiasaan ini memungkinkan guru ISMUBA dan tenaga kependidikan lainnya untuk selalu memberi motivasi kepada siswa sesuai kondisi dan lingkungannya. Kegiatan tercantum dalam program yang disusun oleh koordinator kehidupan Islami dengan tujuan tercapainya ranah kehidupan yang Islami, afektif, 
kognitif, psikomotorik, dan terampil secara seimbang ditiap jenjang kelas (Siswa), guru dan karyawan. Adapun Programnya sebagai berikut:

\begin{tabular}{|c|c|c|}
\hline No & PROGRAM KKI & KETERANGAN \\
\hline \multirow[t]{3}{*}{1} & \multicolumn{2}{|l|}{ BIDANG IBADAH } \\
\hline & 1. Jama'ah Shalat Dzhuhur & \\
\hline & 2. Shalat Dhuha(Latihan Shalat) & \\
\hline \multirow[t]{3}{*}{2} & \multicolumn{2}{|l|}{ TAHFIDZQU \& TUNTAS IQRA } \\
\hline & 1. Tadharus dan Hafalan & Kelas 3-6 \\
\hline & 2. Tadharus Guru & Rapat Sekolah \\
\hline \multirow[t]{4}{*}{3} & \multicolumn{2}{|l|}{ Bidang Pembinaan Prestasi } \\
\hline & $\begin{array}{l}\text { 1. Mengikuti lomba MTQ Dinas } \\
\text { Kemenag Tingkat Kecamatan }\end{array}$ & \\
\hline & 2. Lomba Keagamaan di luar Dinas & \\
\hline & 3. Lomba internal sekolah & \\
\hline \multirow[t]{12}{*}{4} & SUB BIDANG PHBI & \\
\hline & 1. Panitia Ramadhan & \\
\hline & a. Buka Puasa bersama & \\
\hline & b. Pengumpulan zakat & \\
\hline & c. Tadharus & \\
\hline & d. Syawalan & \\
\hline & 2. Idul Adha (Baksos) & $\begin{array}{l}\text { Guru,Karyawan,Wali siswa,siswi } \\
\text { melakukan kegiatan Bakti sosial } \\
\text { kesekolah-sekolah daerah yang } \\
\text { membutuhkan }\end{array}$ \\
\hline & 3. Pengajian Insidental & \\
\hline & a. Tahun Baru Hijriyah & \\
\hline & b. Isra Mi'raj & \\
\hline & c. Maulid Nabi & \\
\hline & d. Menyambut Ramadhan & \\
\hline \multirow[t]{2}{*}{5} & \multicolumn{2}{|l|}{ BIDANG KEHIDUPAN ISLAMI } \\
\hline & 1. Buku hafalan siswa, buku panduan & Membuat buku-buku \\
\hline
\end{tabular}




\begin{tabular}{|c|c|}
\hline Keislaman dan buku Ramadhan & $\begin{array}{l}\text { hafalan,keislaman siswa sebagai } \\
\text { pegangan siswa }\end{array}$ \\
\hline $\begin{array}{l}\text { 2. Pengajian Guru/perbaikan bacaan } \\
\text { qur'an guru }\end{array}$ & $\begin{array}{l}\text { Kurikulum ISMUBA didesain bukan } \\
\text { hanya untuk siswa akan tetapi guru } \\
\text { perlu peningkatan dalam pembelajaran }\end{array}$ \\
\hline $\begin{array}{l}\text { 3. Pengajian PCM, Komite, Wali } \\
\text { Murid, Warga dan warga sekitar }\end{array}$ & $\begin{array}{l}\text { Semua elemen terlibat dalam kegiatan } \\
\text { ini karena tujuan dari kurikulum } \\
\text { ISMUBA adalah bagaimana } \\
\text { menyiapkan kader bangsa dan } \\
\text { Muhammadiyah yang baik } \\
\text { sehinggaperlu sebuah sinergitas } \\
\text { seluruh komponen }\end{array}$ \\
\hline 4. MalamTaqarub & $\begin{array}{l}\text { Memberikan motivasi kepada } \\
\text { siswa,sehingga diharapkan semkin } \\
\text { baik di dalam mengarungi kehidupan }\end{array}$ \\
\hline 5. Religius CAmp & $\begin{array}{l}\text { Siswa diajakan untuk menambah } \\
\text { pengalaman,keilmuan tentang } \\
\text { Keislaman }\end{array}$ \\
\hline 6. Sedekah Merem & $\begin{array}{l}\text { Program membangun karakter } \\
\text { kepedulian sosial semua warga } \\
\text { sekolah }\end{array}$ \\
\hline 7. Duta sedekah merem & $\begin{array}{l}\text { Ada siswa-siswi yang terpilih sebagai } \\
\text { penggerak sedekah di kelasnya } \\
\text { masing-masing }\end{array}$ \\
\hline 8. Pertugas bima sinta & $\begin{array}{l}\text { Siswa-siswa yang membantu guru di } \\
\text { dalam pelaksanaan kegiatan ibadah } \\
\text { dalam rangka Membangun karakter } \\
\text { kepemimpinan sejak dini }\end{array}$ \\
\hline
\end{tabular}

\section{B. Tahap Pelaksanaan Kurikulum}

Tahap pelaksanaan kurikulum berarti ada proses pembelajaran yakni interaksi antara peserta didik dengan guru, teman sebaya, dan lingkungan sekolah, sehingga adanya perubahan menjadi lebih baik. Pada saat interaksi sepeti ini penting untuk menciptakan suatu sistem yang menunjang terbentuknya pembelajaran secara efektif dan efisien. Kegiatan 
pembelajaran yang dimaksud bukan hanya terjadi di dalam kelas namun juga aktifitas diluar kelas dimulai dari peserta didik datang sampai kembali ker rumah masing-masing.

Berdasarkan temuan peneliti bahwa rangkaian kegiatan pembelajaran ISMUBA dan yang terkait di dalamnya meliputi pembelajaran Al-Islam, Kemuhammadiyahan, dan Bahasa Arab, dikelas dimulai dengan salam, pembukaan, penyampaian materi, diakhiri kembali dengan salam, pemberian tugas-tugas, evaluasi untuk mengetahui hasil dari pembelajaran. Selanjutnya kegiatan pengembangan diri peserta didik baik yang terprogram maupun yang tidak terprogram yang meliputi penerapan $5 \mathrm{~S}$ (Senyum,salam,sapa,sopan dan santun), tadharus pagi, Tuntas Iqra', Kelas Tahfidz, Shalat Dhuha, shalat dzuhur berjam'ah, shalat Ashar berjamaah, Sedekah merem, serta pengajian-pengajian Insidental.

Semua rangkaian pelaksanaan kurikulum ISMUBA baik terprogram maupun yang tidak terprogram berjalan dengan baik.

\section{Tahap Evaluasi Kurikulum}

Pada dasarnya semua kurikulum ISMUBA yang telah dilaksanakan baik muatan ALIslam, Kemuhammadiyahan, Bahasa Arab serta program yang berkaitan dengan pengembangan diri semuanya mengacu tujuan dari Muhammadiyah itu sendiri yakni menjadikan semua peserta didik menjadi muslim sebenar-benarnya (Zamroni, 2014). Sehingga dalam pelaksanaan kurikulum ISMUBA ini perlu dilaksanakan dengan konsisten dan berkesinambungan. Hasil temuan yang peneliti dapatkan berdasarkan proses pengumpulann data terdapat beberapa yang belum sejalan dengan perencanaan. Misalnya didalam pembelajaran ISMUBA guru belum sepenuhnya menjadi fasilitator untuk peserta didik tetapi pembelajaran masih bersifat konvensional. Dalam perencanaan kegiatan tahfidz dengan target juz 30 selesai di kelas lima namun terhenti program itu pada walikelas, hal ini berdasarkan hasil wawancara bahwa belum adanya program kegiatan peningkatan kemampuan di dalam pembelajaran untuk semua guru hal ini terkendala waktu. Kegiatan peningkatan kualitas kompetensi guru ini penting karena sekolah-sekolah Muhammadiyah salah satunya SD Muhammadiyah Karangkajen memiliki latar belakang yang beragam tidak semua berangkat dari kader Muhammadiyah.

Selanjutnya, bahwa kegiatan praktek ibadah dan program inilah yang menjadi program unggulan di SD Muhammadiyah Karangkajen hal ini karena disinilah penanaman karakter dimulai. Para siswa adanya ketertarikan, antusias didalam mengikuti praktek ibadah baik shalat dzuhur berjamaah, shalat dhuha, dan shalat ashar berjamaah. Hal ini terlihat dari peserta didik yang belum waktunya sudah mempersiapkan diri menuju ketempat-tempat di 
mana ibadah shalat itu dilaksanakan. Hal yang kurang adalah dari segi pendampingan yang belum berjalan dengan baik terlihat dari jadwal pendampingan yang tidak sesuai dengan praktik dilapangan. Temuan lainnya yang peneliti dapatkan yakni pembiasaan sedekah oleh semua warga sekolah. Hasil observasi dan wawancara dilapangan menunjukkan bahwa siswa membiasakan untuk bersedekah pagi. Dapat dilihat dari hasil pengumpulan jumlah infaq yang signifikan setiap bulannya mengalami kenaikan kemudian dalam penggunaan dana infaq salah satunya untuk operasional seluruh kegiatan Keislaman.

\section{KESIMPULAN}

Berdasarkan hasil penelitian dan pembahasan tentang implementasi Kurikulum ISMUBA dapat diambil kesimpulan sebagai berikut: (1) Kurikulum ISMUBA SD Muhamamdiyah Karangkajen Yogyakarta adalah kurikulum operasional yang disusun dan dilaksanakan oleh masing-masing satuan pendidikan. Kurikulum ini terdiri dari tujuan pendidikan tingkat satuan pendidikan, struktur dan muatan kurikulum tingkat satuan pendidikan baik yang terprogram maupun yang tidak terprogram, kalender pendidikan, dan silabus. (2) Implementasi Kurikulum ISMUBA SD Muhammadiyah Karangkajen Yogyakarta dilakukan dengan tiga tahapan perencanaan, pelaksanaan,dan evaluasi kurikulum. Pada tahap perencanaan semua program guru terlibat di dalamnya dan lengkap dalam penyusunannya. (3) Evaluasi dalam implementasi kurikulum ISMUBA ini lebih kepada teknis pelaksanaan yakni belum adanya kesamaan visi misi guru dan karyawan di dalam melaksanakan program sekolah. (4) Terkait dengan hasil implementasi Kurikulum ISMUBA SD Muhammadiyah Karangkajen dari segi pengetahuan hasil belajar siswa masih sangat rendah terlihat dari hasil belajar siswa yang belum memenuhi kriteria ketuntasan belajar. Dari segi pengamalan praktek ibadah harian siswa sangat antusias untuk mengikutinya baik shalat tepat waktu,pengajian,sedekah dan hafalan-hafalan Al-Qur'an. 


\section{DAFTAR PUSTKA}

Ansyar, M. (2015). Kurikulum. Jakarta: Fajar Interpratama Mandiri.

Dinn Wahyudin. (2014). Manajemen Kurikulum. Remaja Rosyda karya.

Hamalik, O. (1999). Kurikulum Dan Pembelajaran. Jakarta: Bumi Aksara.

Miller, J. . \&W. S. (1985). Curriculum perspective and practice. New York and London Longman.

Nana Syaodih, S. (2010). Metode Penelitian Pendidikan. Bandung: Remaja Rosyda karya.

Sugiyono. (2012). MetodePenelitian pendidikan.

Suwandi, B. (2008). Memahami penelitian Kualitatif. Jakarta: Rineka Cipta.

Zamroni. (2014). Pemikiran Pendidikan Muhammadiyah. Yogyakarta: Ombak.

(2003). Undang-undang Sisdiknas 2003.

(2006). Permendiknas. 